\title{
Ultrasonography and Tonometry for the Assessment of Human Arterial Stiffness
}

\author{
Graeme J. Koelwyn¹, Katharine D. Currie², \\ Maureen J. MacDonald ${ }^{2}$ and Neil D. Eves ${ }^{1}$ \\ ${ }^{1}$ School of Health and Exercise Sciences, University of British Columbia \\ ${ }^{2}$ Department of Kinesiology, McMaster University \\ Canada
}

\section{Introduction}

The structure and function of the human vasculature is integral to the efficacy of the cardiovascular system. In particular, arteries function as both a reservoir to dampen oscillations from the pumping heart, as well as a conduit to transport blood to the periphery. With age and disease, alterations in the composition of the arterial wall can occur. This can result in arteries becoming more resistant to wall deformation, referred to as arterial stiffness, which can have significant implications for the development of cardiovascular disease. Due to the emergence of arterial stiffness as a measure of cardiovascular disease risk, a number of non-invasive techniques have been developed, which include the use of ultrasonic assessment. These techniques are highly effective, reliable, and well validated, and consider stiffness both locally (most commonly measured at the carotid artery) as well as regionally (most commonly measured through the aorta) in the arterial tree. The assessment of arterial stiffness is critical to our understanding of the overall vascular health, and is the focus of this chapter.

\section{Anatomy and physiology of the blood vessel}

\subsection{Anatomy of the artery}

The human artery is comprised of a lumen surrounded by a series of concentric layers, which work together cohesively to assist in propagating blood from the heart to the periphery. The arterial wall itself is divided into 3 major regions: the tunica intima, media, and adventitia (Figure 1). The intima is comprised in part by the vascular endothelium, which lines the interface with the lumen. The vascular endothelium is a single layer of simple squamous epithelial cells that play a critical role in the regulation of smooth muscle tone through the release of several vasoactive substances. Adjacent to the endothelium lies a thin layer of elastin and collagen fibers, which attach to the internal elastic lamina, an elastic tissue that forms the outermost layer of the intima region. The tunica media is a more complex structure, and contains smooth muscle amidst a structure of elastin and collagen, which together act as a homogenous unit (Dobrin, 1999). A surrounding structure of thicker elastin bands wraps circumferentially with finer bands of elastin connecting them, and 
collagen dispersed in the intervening spaces with some inherent slack. The collagen also attaches to the smooth muscle, which lies internal to the surrounding structure. This latticework provides a flexible "safety net" for the blood vessels to prevent damage to the wall of the artery, especially at high transmural pressures. Finally the outermost region, the tunica adventitia, is separated from the tunica media by the outer elastic lamina, and is a layer of elastin and collagen that merges with the surrounding tissues.

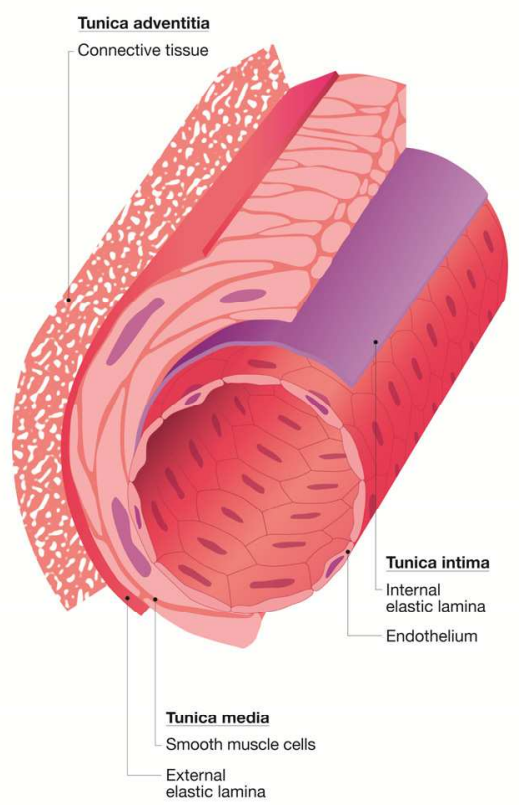

Fig. 1. Anatomy of a blood vessel

\subsection{Functions of the arterial system}

Arteries act as a conduit system to transport blood through the body, and dampen oscillations from the pulsatile ejection of blood to provide steady flow throughout the arterial tree. There are 3 separate anatomical arterial regions addressing these functions (Nichols \& O'Rourke, 2005). First, large elastic arteries such as the aorta provide the predominant cushioning reservoir for blood flow. Second, large muscular arteries act as the conduit for blood to the periphery and actively modify wave propagation through smooth muscle tone regulation. Finally, arterioles function to alter peripheral artery resistance, and subsequently aid in the maintenance of mean arterial pressure and delivery of a continual flow to required systems and subsequent capillary beds.

Several models have been proposed for the functioning of the arterial system, with the propagative/distensible tube model considered superior (Laurent et al., 2006; O'Rourke et al., 2002). The propagative/distensible tube model consists of a single distensible tube with one end representing peripheral resistance, and the other receiving blood in pulses from the left ventricle (Nichols \& O'Rourke, 2005). The pressure wave generated from the heart 
travels down the tube and is propagated and dampened by the viscoelastic wall of the vessel. When applying this theory to the entire arterial tree several phenomena need to be considered. As the pulse travels down the arterial tree it becomes amplified. This amplification is caused by the progressive increase in stiffness of the arteries distally from the heart (Learoyd \& Taylor, 1966) and the branching, bifurcations, and non-linearity in the vascular tree that produce sites where the pressure wave can be reflected. These reflections return in the opposite direction and amplify the pressure signal. Reflection sites are closer to the pulse wave in the periphery (greater branching) than in the central arteries, and amplification is therefore greater (known as the 'amplification phenomena') (Laurent et al., 2006). Thus, the pressure wave at any given location is the result of the summation of the incident and reflected wave (Figure 2) (Davies \& Struthers, 2003; O'Rourke et al., 2002), and depending on the elasticity of the vasculature, can create various pressure waveforms.

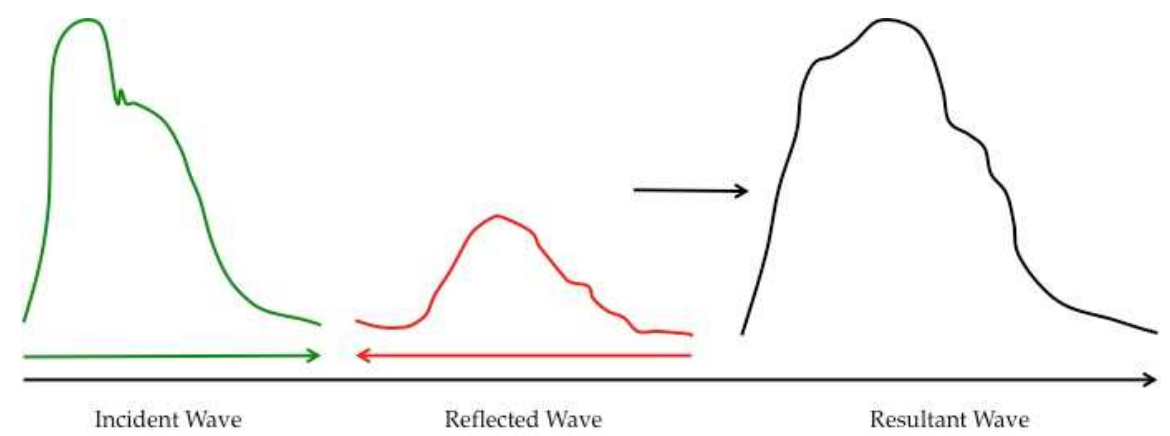

Fig. 2. The pressure waveform is a result of the summation (right) of the incident wave (left) travelling toward the periphery and combining with the reflected wave (middle) returning from the periphery.

The composition of the arterial wall, in particular the elastin and collagen content, changes from central to peripheral arteries. Starting in the proximal aorta, elastin is the dominant component. At the abdominal aorta the content of collagen and elastin appears similar, and by the periphery collagen becomes dominant (Harkness et al., 1957). As collagen is 300 times stiffer than elastin (elastic modulus $1000 \times 10^{6}$ dyne/ $\mathrm{cm}^{2}$ vs. $5 \times 10^{6}$ ) (Armentano et al., 1991), the altering arterial wall composition causes an increasing 'stiffness gradient' down the arterial tree. For example, in the central arteries, up to $50 \%$ of the stroke volume ejected from the heart is momentarily stored in the aorta and large elastic arteries. Approximately $10 \%$ of the energy produced by the heart is used to distend the arteries during systole. The elastic walls of the artery store the energy, and subsequently use it to recoil the vessel wall during diastole (London \& Pannier, 2010), thus ensuring continuous flow to the stiffer, more collagen based, peripheral arteries. For this dampening in the central arteries to be most efficient, the energy needed to distend the wall needs to be as low as possible (London \& Pannier, 2010), which not only depends on elasticity (and high elastin content), but also the geometry of the vessel walls.

Elastin and collagen cause the pressure-diameter relationship at any specific area on the arterial tree to be non linear (Figure 3) (Armentano et al., 1991). At low distensions, pressure 
is mainly governed by elastin fibers, which are quite compliant and the resulting curve is more linear, where at higher tensions it is governed by the supporting latticework of collagen content, which is much stiffer, resulting in a steeper slope (a greater required pressure for a given diameter change) (Lanne et al., 1992).

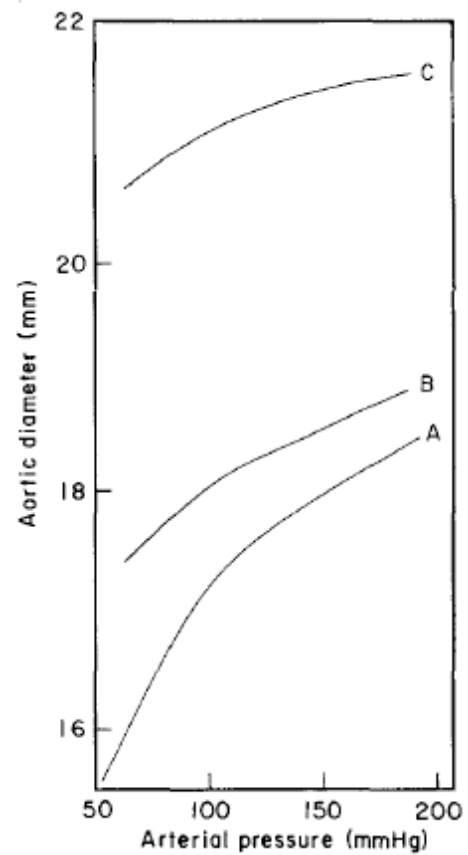

Fig. 3. Pressure-diameter relationship of the abdominal aorta in (A) young (mean 25 yrs), (B) middle aged (mean 51 yrs) and (C) elderly (mean 70 yrs) humans. Reprinted with permission (Lanne et al., 1992)

\section{Arterial stiffness}

\subsection{Development of arterial stiffness}

Considerable research supports the measurement of arterial stiffness as a highly relevant tool in the assessment of vascular structure. Degenerative stiffness of the arterial wall is considered arteriosclerosis, and is distinguishable from atherosclerosis, which is the occlusive result of endovascular inflammatory disease, lipid oxidation and plaque formation (Cavalcante et al., 2011). Even in healthy, young individuals, arterial stiffness is heterogeneous throughout the arterial tree, as amplification and the natural stiffness gradient result in more elastic central and stiffer peripheral arteries (London \& Pannier, 2010). Arteries in humans, however, also stiffen with healthy ageing and disease (discussed later in the chapter), affecting predominately the aorta and proximal elastic arteries, and to a lesser degree the peripheral arteries (O'Rourke et al., 2002), and can even result in a minimization or reversing of the stiffness gradient (Benetos et al., 1993; Boutouyrie et al., 1992; Laurent et al., 2006). This regional age associated stiffening has been attributed to 
longstanding pulsation that induces greater cycles of stress in the central arteries (Adji et al., 2011; Lee \& Oh, 2010).

With age and disease, degeneration of the media in the central arteries appears to be the primary structural change associated with chronic increases in arterial stiffness. Fatigue and fracture of elastin and collagen fibers occur. These structural changes to the elastin and collagen functional unit are determined by the extent of circumferential strain, which is greater centrally, and length of strain exposure (number of cardiac cycles) (McEniery et al., 2010). The orderly arrangement of elastic lamellae disappears, and is replaced by thinning, fragmented elastin, greater foundations of collagen (Laurent \& Boutouyrie, 2007; Najjar et al., 2005; Zieman et al., 2005) and medial calcification (elastocalcinosis) (Atkinson, 2008). Other age and disease associated changes in the arterial wall include specific changes in the smooth muscle cell connections (Laurent et al., 2005), and inflammation in the form of acute systemic (Vlachopoulos et al., 2005) and chronic (Roman et al., 2005) inflammatory disease.

A stiffer artery propagates a pulse wave faster than a more compliant vessel. This leads to earlier return of the reflected wave, which amplifies systolic pressure and decreases diastolic pressure (Figure 4). Increased systolic pressure places a greater stress (distending pressure) on the wall of the vessel, which over time can accelerate the stiffening and remodeling process. A decrease in diastolic pressure can reduce coronary perfusion pressure, reducing coronary blood flow reserve, which may be a possible link to increase cardiac event risk in

\section{A. Decreased arterial compliance}

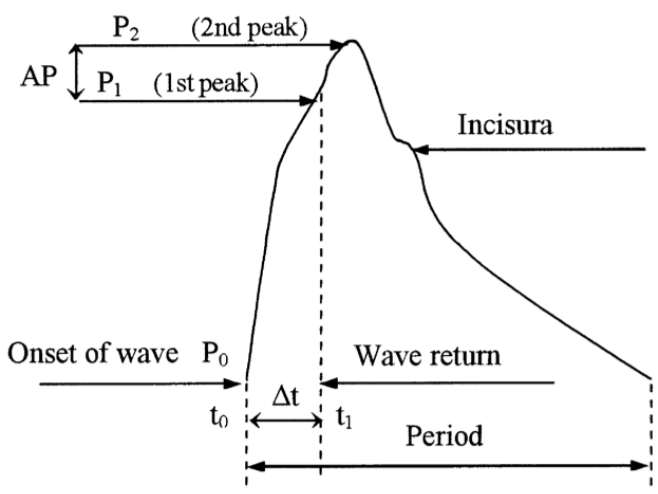

\section{B. Increased (normal) arterial compliance}

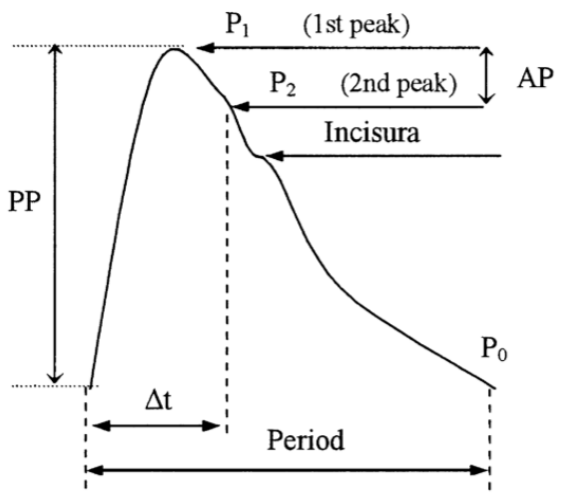

Fig. 4. Effect of decreased (A) and normal (B) arterial compliance on the pulse waveform. $\mathrm{P}_{0}$ : end-diastolic pressure; $\mathrm{P}_{1}$ : early systolic peak; $\mathrm{P}_{2}$ : late systolic peak (from reflected wave); $\triangle t$ : time from onset of pressure wave $\left(t_{0}\right)$ to return of reflected wave $\left(t_{1}\right)$; PP: pulse pressure. Reprinted and modified with permission AP: augmentation of systolic aortic pressure (Papaioannou et al., 2004) 
subjects with elevated arterial stiffness (Saito et al., 2008). Increased arterial stiffness also results in failure to suppress the pulse oscillations downstream from the central arteries. Decreased pulse suppression potentially increases the risk for damage to micro vascular beds in highly perfused organs such as the brain and kidneys (O'Rourke \& Safar, 2005), and has important implications for risk of stroke and renal failure.

Increased arterial stiffness with age and disease is partially compensated for by remodeling of the arteries, through luminal enlargement (Boutouyrie et al., 1992) and wall thickening (Cheng et al., 2002; Zieman et al., 2005). It appears that endothelial dysfunction, which can occur from a decrease in nitric oxide (NO) release, increase in oxidative stress, and/or a decrease in antioxidant capacity with age or disease, is the earliest change in the vasculature that can lead to advancing vascular disease (Taddei et al., 2001; Widlansky et al., 2003). Decreased NO leads to increasing vascular tone of the small arteries responsible for major changes in total peripheral resistance (arterioles). Increasing vascular tone leads to structural and functional changes upstream in the larger arteries, resulting in stiffening and remodeling, increasing blood pressure (in particular pulse pressure), as well as atherosclerotic plaque development and additional functional abnormalities (Folkow, 1995). However, this temporal sequence in the manifestation of arterial disease is not always present, as structural changes can present without obvious functional changes, and these structural changes are not always homogenous across the vascular tree (Naghavi, 2009).

Arterial stiffness is emerging as one of the most important determinants of increased systolic blood pressure and pulse pressure in ageing and disease. It is the root cause of a number of cardiovascular complications including left ventricular hypertrophy, left ventricular failure, aneurism formation and rupture, and is a major contributor to atherosclerotic and small vessel disease, which can lead to stroke, myocardial infarction and renal failure (Nichols \& O'Rourke, 2005). Central artery stiffening, in particular aortic stiffening, is strongly related to cardiovascular events, independent of age, arterial pressure, and conventional risk factors for cardiovascular disease (Adji et al., 2011), as well as future hypertension risk after correcting for systolic blood pressure, age, sex, body mass index, heart rate, total cholesterol, diabetes, smoking, alcohol and physical activity (Dernellis \& Panaretou, 2005). In fact, stiffening of the aorta rather than left ventricular myocardial abnormalities appears to be the predominant cause of cardiac failure with age (Levy \& Brink, 2005) as it produces higher systolic pressures in the aorta and left ventricle. These elevated systolic pressures present a high load on the ventricle, predisposing it to increased systolic wall stress and remodeling, which can progress to dysfunction and failure (Adji et al., 2011).

A variety of techniques for measuring arterial stiffness have been developed. In particular, with the use of ultrasonography, two techniques have been utilized extensively and have been validated for measuring central arterial stiffness non-invasively. In the measurement of regional arterial stiffness, pulse wave velocity has emerged as the gold standard (Laurent et al., 2006) for the noninvasive assessment of arterial stiffness, while local arterial stiffness measures, specifically at the carotid artery, have emerged as an important tool for the mechanistic study of vascular structure and function. Although researchers and clinicians extensively use arterial stiffness measures, a number of potential limitations to these techniques have been identified (Laurent et al., 2006; O'Rourke et al., 2002). Assumption of a homogenous vascular wall when it is heterogeneous in nature, the use of different locations for measures of pressure and arterial diameter, and failing to account for the altering effects 
of heart rate (which affects the rate that pulse pressure amplifies) (Wilkinson et al., 2002) and cardiac contractility (O'Rourke et al., 2002) are common oversights in measurement. Furthermore, nervous system activity, fluctuations in autonomic control, vasoactive substances such as nitric oxide, and hormones influence vascular smooth muscle, which can also influence arterial stiffness. Muscular arteries, particularly smaller arteries (O'Rourke et al., 2002), are also subject to spontaneous vasomotor changes that affect both diameter and stiffness (Hayoz et al., 1993). Despite these limitations, measures of arterial stiffness are considered an integral tool in the noninvasive assessment of vascular structure and function, and are an important determinant for cardiovascular risk.

\subsection{Local arterial stiffness and measurement}

\subsubsection{Viscoelastic properties of the arterial wall}

The arterial wall is considered to be viscoelastic, as it contains both elastic and viscous properties (Nichols \& O'Rourke, 2005). When a stress is applied (a force that produces deformation) to a perfectly elastic material, it will regain its original form when the stress is removed. In an artery, however, wall viscosity is present, which leads to the wall retaining part of the deformation (London \& Pannier, 2010). This is partially responsible for hysteresis seen in the pressure-diameter loop (Figure 5). Unfortunately the viscosity of the wall is difficult to measure in humans, and therefore the elasticity component of the arterial wall is what has been extensively evaluated.

\section{Arterial diameter-pressure curve}

\section{Diameter (mm)}

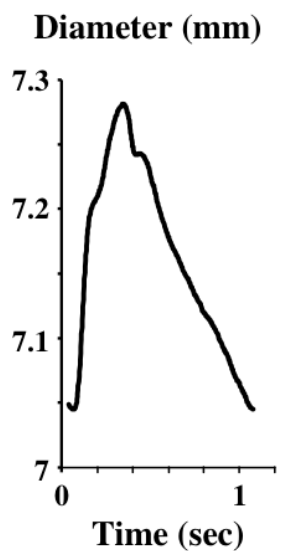

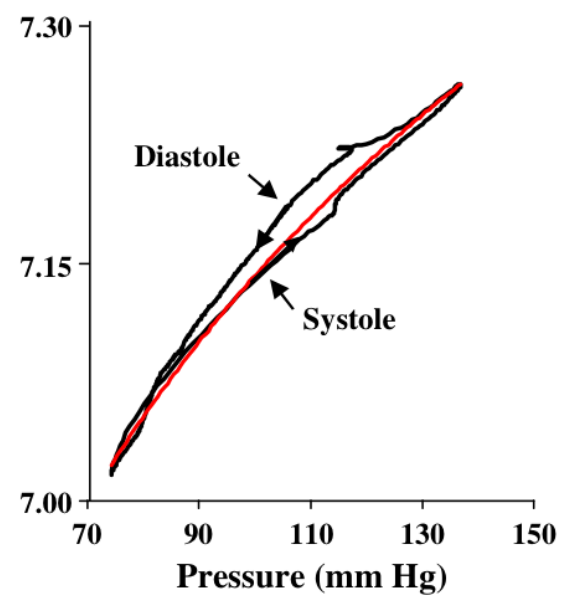
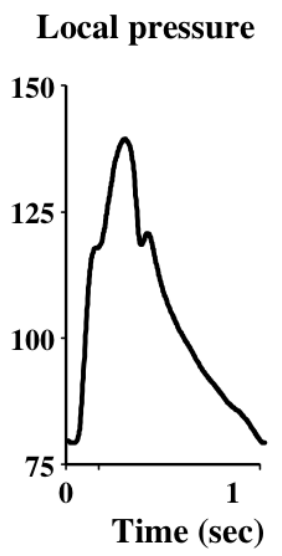

Fig. 5. Diameter-pressure curve (middle) derived from the diameter (left) and local pressure (right) of the common carotid artery. Differences in systole and diastole represent the energy dissipation due to viscous properties of the arterial wall. The red line is the averaged pressure-diameter curve. Reprinted and modified with permission (London \& Pannier, 2010) 


\subsubsection{Calculations of local arterial stiffness}

The elasticity of the arterial wall can be gauged by understanding the stress/strain relationship. While stress is the force producing deformation, strain is the resulting deformation incurred as a percentage change in length (Cavalcante et al., 2011). Strain therefore is dimensionless, and the stress/strain ratio is known as the elastic modulus, or Young's modulus (O'Rourke et al., 2002). In an artery, assuming the segment is a cylindrical tube with a circular luminal cross-section (Pannier et al., 2002; Reneman et al., 2005), compliance is considered the absolute change in volume (strain) due to a change in pressure (stress). Distensibility takes into account the initial dimensions of the artery, and is considered the relative change in volume for a given pressure. The equations are as follows:

$$
\begin{gathered}
\text { Compliance }=\frac{\Delta \mathrm{CSA}}{\mathrm{PP}}=\frac{\Pi \mathrm{r}^{2}-\Pi^{2}}{\mathrm{PP}}=\frac{\Pi\left(\frac{\mathrm{d} \max }{2}\right)^{2}-\Pi\left(\frac{\mathrm{d} \text { min }}{2}\right)^{2}}{\mathrm{PP}} \\
\text { Distensibility }=\frac{\Pi\left(\frac{\mathrm{d} \max }{2}\right)^{2}-\Pi\left(\frac{\mathrm{d} \min }{2}\right)^{2}}{\Pi\left(\frac{\mathrm{d} \min }{2}\right)^{2} \times \mathrm{PP}}
\end{gathered}
$$

where dmax is the maximum systolic diameter, dmin is the minimum diastolic diameter, and PP is the carotid pulse pressure. Compliance and distensibility can both be estimated as a change in radius, diameter, flow, or cross sectional area for a given change in pulse pressure, measured at the same site (Nichols \& O'Rourke, 2005). The resistance to deformation is known as stiffness, which in turn is the reciprocal of compliance.

Local arterial stiffness of the central arteries is directly determined, as denoted from a change in pressure producing a given change in volume (Laurent et al., 2006) (Figure 6). In the large elastic arteries (i.e. the carotid artery or aorta) the relationship between lumen cross sectional area and change in pressure is linear (Meinders \& Hoeks, 2004) and the error from this assumption is quite small (Reneman et al., 2005). In stiffer peripheral muscular arteries this error can be large (Reneman et al., 2005), therefore direct measures done at the carotid artery and aorta for determining local stiffness have been extensively explored.

Young's modulus, or the incremental elastic modulus ( $\left.E_{\text {inc }}\right)$, outlined in equation [3], has been used extensively (Nichols \& O'Rourke, 2005). It estimates the elastic properties of the arterial wall by taking into account it's thickness. Current measuring techniques unfortunately cannot differentiate the load bearing section of the wall (media/adventitia) from the non-load bearing portion (intima). Intima-media thickness (IMT) is used as a surrogate for wall thickness, as the adventitia is indistinguishable from surrounding structures with ultrasound imaging techniques. The assumptions are that the IMT is load bearing, and that the arterial wall is homogeneous (Adji et al., 2011; O'Rourke et al., 2002). Thus caution should be exercised in using Young's modulus as current measurements can be imprecise and unrealistic (O'Rourke et al., 2002). 


\section{Systole}
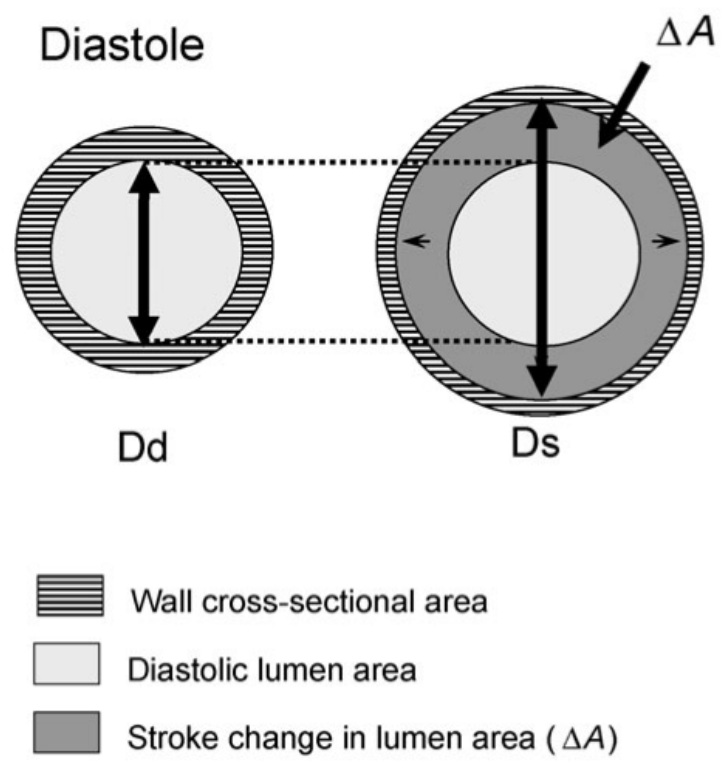

Fig. 6. Measurement of local arterial stiffness: change in luminal cross sectional area $(\triangle \mathrm{A})$ for a given change in pressure (diastole to systole). Reprinted and modified with permission (Laurent et al., 2006)

$$
E_{\text {inc }}=\frac{3\left(\frac{1+\Pi\left(\frac{d \min }{2}\right)^{2}}{\Pi\left(\frac{\mathrm{de}}{2}\right)^{2}-\Pi\left(\frac{\mathrm{di}}{2}\right)^{2}}\right)}{\Pi\left(\frac{\mathrm{d} \min }{2}\right)^{2} \times \mathrm{PP}}
$$

where de is the external diameter and di is the internal diameter, measured in diastole.

Peterson's elastic modulus (Peterson et al., 1960), outlined in equation [4], is different from Young's elastic modulus. It assumes a linear stress strain relationship, is inversely related to arterial distensibility, and needs to be specified at a given blood pressure (Cheng et al., 2002). In turn, an equation that provides an index of arterial compliance independent of distending pressure is the $\beta$ stiffness index (Hirai et al., 1989), outlined in equation [5], where SBP is systolic blood pressure, and DBP is diastolic blood pressure. 


$$
\begin{aligned}
\text { Peterson } & =\frac{\Pi\left(\frac{\mathrm{d} \text { min }}{2}\right)^{2} \times \mathrm{PP}}{\Pi\left(\frac{\mathrm{d} \max }{2}\right)^{2}-\Pi\left(\frac{\mathrm{d} \min }{2}\right)^{2}} \\
\beta & =\frac{\ln \left(\frac{\mathrm{SBP}}{\mathrm{DBP}}\right)}{\left(\frac{\mathrm{d} \max -\mathrm{d} \min }{\mathrm{d} \min }\right)}
\end{aligned}
$$

\subsubsection{Measurement of local arterial stiffness with ultrasound and tonometry}

Ultrasound is a common tool used in the non-invasive assessment of the elastic properties of the arterial wall. Many devices have been developed to determine vascular diameters and IMT. These include echo tracking software (Hoeks et al., 1990; Tardy et al., 1991), which use radiofrequency signals to obtain a high precision image, as well as B-mode ultrasound equipped with a high-resolution linear array transducer (Currie et al., 2010; Nualnim et al., 2011; Redheuil et al., 2010; Tanaka et al., 2000) in combination with various edge detection and image analysis software. Both methods have been shown to have high agreement for assessing vessel diameter (A. S. Kelly et al., 2004). Measurement of IMT using non-invasive ultrasound systems is also an important tool and is used as a surrogate measure for wall thickness in measures of elasticity of the arterial wall such as Young's modulus. IMT is also often used as an indicator for cardiovascular disease (O'Leary et al., 1999) and has been employed in clinical studies (Molinari et al., 2010; Simon et al., 2002).

Most commonly, B-mode ultrasound images are collected at a minimum of 10 frames/sec with a 7.5-11 MHz linear array transducer positioned longitudinally to the common carotid artery with collection $\sim 1-2 \mathrm{~cm}$ below the bifurcation of the external and internal carotid arteries. Analysis of time points associated with the maximal diameter in systole and the minimum diameter in diastole are selected and diameters are determined by measurement of the far wall from the interface of the lumen and intima to the near wall interface of the adventitia and media (Tanaka et al., 2000). Imaging of media-adventitia interface of the near wall is used, as the intima-lumen interface can be difficult to obtain. Determination of arterial diameters can be made manually using calipers, or with edge-detection software. Most edge-detection software determines the arterial diameter by identifying the arterial wall within a selected region of interest, based on the contrasting intensity of brightness between the arterial wall boundary and the lumen (Currie et al., 2010; Peters et al., 2011). Measurements are made at numerous points within the region of interest (typically $\geq 100$ points), thereby increasing the precision of the measurement. Other software uses the radiofrequency signals generated from the tissue echo reflections to detect boundaries in tissue density. The radiofrequency detection has the added advantage of not being 
dependent on the post-processing of the B-mode images but is less commonly available (Woodman et al., 2001).

Local arterial measures also require measurement of local blood pressure. Applanation tonometry has been shown to produce near-identical pulse waveforms as those performed invasively (R. Kelly et al., 1989). Applanation tonometry uses a probe that incorporates a high fidelity strain gauge transducer which records continuous pressure waveforms in an artery. It is placed over the greatest area of pulsation, and requires support from solid structures (bone, bone plus ligaments) to flatten the artery slightly to produce a consistent and reproducible signal (R. Kelly et al., 1989). Based on the assumption that diastolic and mean blood pressure are constant through the arterial tree (Nichols \& O'Rourke, 2005), Kelly and Fitchett developed a system of approximation of local arterial pressure using a tonometer (R. Kelly \& Fitchett, 1992), which has been shown to provide the highest accuracy compared to invasive methods (Van Bortel et al., 2001). As baseline levels acquired by the tonometer are subject to hold down pressure, diastolic and mean blood pressures are equated to brachial blood pressures. Local systolic blood pressure is then determined by the extrapolation of the maximal tonometer signal and calibrated pressures, due to the amplification in systolic blood pressure (Nichols \& O'Rourke, 2005). An example of this is provided in Figure 7. Ideally carotid artery pressures should be calibrated to concurrent brachial blood pressures measured continuously using various automated oscillometric blood pressure devices (Ex. Finometer (Finapres Medical Systems B.V.; Amsterdam, The Netherlands), Nexfin (BMEYE; Amsterdam, The Netherlands), CMB-700 (Colin Medical Instruments; San Antonio, TX, USA)), which correct to brachial blood pressure from either finger or radial artery waveforms. When this is not possible, carotid artery pressures can

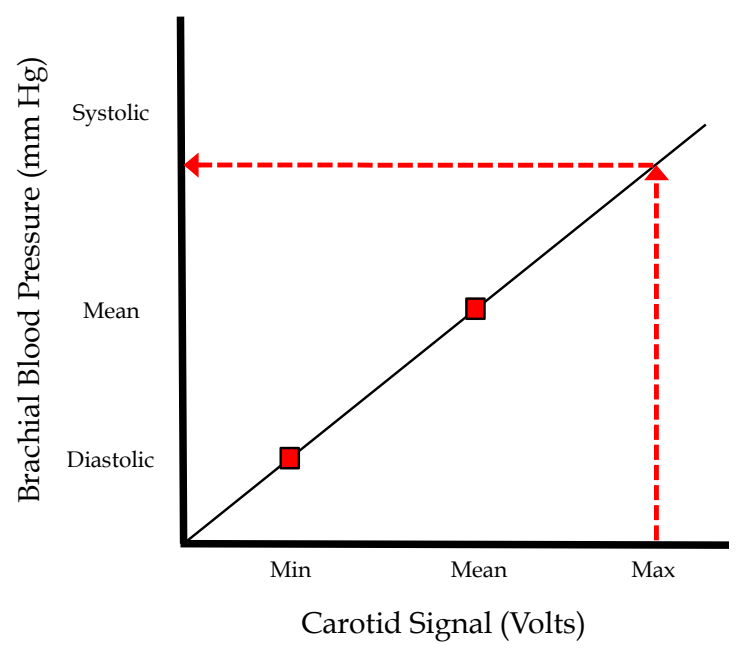

Fig. 7. Approximation of carotid systolic pressure. Minimum and mean carotid artery tonometry values are equated to the diastolic and mean brachial artery blood pressures (red squares), and the equation of the line connecting the points is generated. The pressure (y-axis) at which the maximum carotid artery tonometry value intersects with this line is identified as the predicted carotid artery systolic blood pressure. 
also be calibrated to discrete brachial blood pressures collected using a manual sphygmomanometer or an automated oscillometric device. It should be mentioned that previous investigations (Barenbrock et al., 2002; Dijk et al., 2005; Tsivgoulis et al., 2006) have used brachial pulse pressures in the calculation of arterial stiffness measurements when the collection of localized pulse pressure is not available; however, this is not recommended.

Common carotid artery diameter and simultaneous carotid artery blood pressures are collected for 10 cardiac cycles (Currie et al., 2010) in the supine position following at least 10 minutes of quiet rest. Assessments should be performed in a temperature-controlled room, at the same time of day (for repeated measures), and individuals should abstain from caffeine, food consumption, and smoking for at least 3 hours, and alcohol consumption for at least 10 hours prior to testing (Laurent et al., 2006). Section 4 will discuss the association between local measures of carotid artery stiffness and disease; however; it has been suggested that local measures of arterial stiffness be used in mechanistic studies in pathophysiology, pharmacology, and therapeutics, rather than epidemiological studies moving forward (Laurent et al., 2006).

\subsubsection{Validity, reliability, and reproducibility of local arterial measurements}

Carotid measurements have been validated in clinical studies (Boutouyrie et al., 1999), as both ultrasound imaging for detection of lumen diameter and IMT (Gamble et al., 1994; Hoeks et al., 1990; Hoeks et al., 1997; A. S. Kelly et al., 2004) and use of applanation tonometry (R. Kelly et al., 1989) has been shown to be accurate and reproducible. Between visit coefficient of variation for distensibility measures using B-mode ultrasound imaging techniques is approximately $10 \%$ (Kanters et al., 1998; Liang et al., 1998), whereas IMT measures have a coefficient of variation of 2.6-2.8\% (Currie et al., 2010; Liang et al., 1998).

\subsubsection{Limitations of local arterial measurements}

There are several limitations when measuring local arterial stiffness. Applanation of an artery requires a firm background surface to flatten the artery and low levels of subcutaneous fat to avoid dampening of the pulse (Reneman et al., 2005), therefore acquiring a pulse can be an issue in obese individuals. Local stiffness measures using ultrasound are also less sensitive than MRI measures of age-related ascending aortic stiffness in individuals free of cardiovascular disease (Redheuil et al., 2010). However, ultrasound is still a highly accessible clinical tool, and its use for determination of stiffness in the carotid artery is an accepted technique in the assessment of central artery stiffening. Finally, the predictive capacity of carotid stiffness measures for vascular events in patients with manifest arterial disease has been shown to be limited (Dijk et al., 2005). Although, brachial pressures were used in this study as a surrogate of local carotid pressure, therefore caution should be used when considering this result (see Figure 7).

\subsection{Regional arterial stiffness and measurement}

Regional arterial stiffness can be assessed using pulse wave velocity (PWV), which is commonly defined as the speed of the arterial pulse wave throughout the vasculature (O'Rourke et al., 2002). As previously described, ventricular ejection produces an incident pressure wave, which moves away from the heart and towards the peripheral vasculature at 
a finite speed. The assessment of how fast the incident wave travels, or its PWV, can provide information about the stiffness of different arterial segments. The faster the PWV, the stiffer the artery, which is addressed by the Moens-Korteweg equation (O'Rourke, 2006):

$$
P W V=\sqrt{\frac{E h}{2 R p}}
$$

where E represents the intrinsic elastic properties of the vessel (Young's modulus in the circumferential direction), $\mathrm{p}$ is the blood density, and $(\mathrm{h} / 2 \mathrm{R})$ is the ratio of arterial wall thickness to vessel diameter. However, PWV can be determined practically and noninvasively using a variety of pulse detection tools including continuous wave or pulsed wave Doppler ultrasound.

\subsubsection{Measurement of regional arterial stiffness}

The assessment of PWV involves recording pulse waves at two different arterial sites, for a minimum of 10-15 seconds, to ensure measurement across at least one respiratory cycle (Van Bortel et al., 2002). Traditionally PWV is separated into central and peripheral measurements to account for differences in vascular composition of different portions of the vascular tree. Central PWV, also referred to as aortic PWV, provides an index of stiffness of the large elastic arteries, and is commonly measured as the PWV between the carotid and femoral arterial sites. Peripheral pulse wave velocity provides an index of stiffness of the medium sized muscular arteries, and can be separated into upper limb and lower limb measures. Upper limb assessments typically involve pulse detection at the carotid and brachial or radial arterial sites, where as lower limb PWV can be measured from the femoral artery to either the dorsalis pedis or posterior tibial arterial sites. Doppler ultrasound can be used to collect blood velocity signals at any of the sites listed above. However, aortic PWV can also be determined by collecting blood velocity signals at the suprasternal notch (root of the left subclavian artery), and the umbilicus (near the bifurcation of the abdominal aorta) (Lehmann et al., 1998).

\subsubsection{Calculations of regional arterial stiffness}

PWV is calculated using the following equation:

$$
\mathrm{PWV}=\frac{\mathrm{D}}{\Delta \mathrm{t}}
$$

where $\mathrm{D}$ is the distance between measurement sites, and $\Delta \mathrm{t}$ is the pulse transit time.

Distance is measured along the surface of the body with anthropometric measuring tape, using specific anatomical landmarks. Central PWV measurements can be made using one of the following pathways: 1) total distance between carotid (carotid artery site to sternal notch) and femoral (sternal notch to inferior border of the umbilicus + inferior border of the umbilicus to the femoral artery site) arterial sites, 2) subtracting the distance of the carotid artery site from the total distance, or 3) subtracting the distance of the carotid artery site 
from the femoral artery site, which has recently been shown to have the best agreement with invasive measures (Weber et al., 2009). When standardization between distance measurement pathways is needed, central distance values can be converted to the total distance between carotid and femoral arterial sites (The Reference Values for Arterial Stiffness' Collaboration, 2010). PWV can then be multiplied by 0.8 to correct for the overestimation (The Reference Values for Arterial Stiffness' Collaboration, 2010). For upper limb PWV, the distance between the carotid artery site to the sternal notch is subtracted from the distance between the sternal notch and the upper limb site (brachial or radial artery site), which is measured when the arm is abducted 90 degrees. Lower limb measurements are made from the femoral artery site along the leg to either the dorsalis pedis or posterior tibial artery site.

The pulse transit time is determined as the time delay between the arrival of the pulse wave at the two arterial sites, and is calculated using the following equation:

$$
\Delta \mathrm{t}=\mathrm{T}_{2}-\mathrm{T}_{1}
$$

where $T_{2}$ is the pulse arrival time at the distal site, and $T_{1}$ is the pulse arrival time at the proximal site. Time at each site can be determined online or offline. Online analysis uses the ECG trace and manual calipers to determine the time at the R-spike and at the arrival of the blood velocity waveform, which is commonly identified as the foot of the waveform. By subtracting the two values, you can determine time for that arterial site (either $T_{1}$ or $T_{2}$ ). To perform offline analysis, the raw audio signal from the color wave or pulsed wave Doppler ultrasound is outsourced to an external data collection system. The most reliable techniques include identifying, 1) the intersecting point between the tangent to the initial systolic upstroke of the blood velocity signal, and the horizontal line through the minimum point, and 2) the second derivative of the blood velocity signal, where the arrival of the waveform is identified as the maximum value (Figure 8) (Chiu et al., 1991). However, identification of the arrival of the pulse wave using derivatives has been criticized, since the shape of the waveform changes with heart rate fluctuations (Nichols \& O'Rourke, 2005), altering where the peak of the derivative identifies. The arrival of the waveform can also be identified based on the phase velocity theory, which suggests the foot of the waveform is primarily composed of frequencies between 5 and $30 \mathrm{~Hz}$, near the $30 \mathrm{~Hz}$ value (McDonald, 1968; Munakata et al., 2003). By filtering out the lower and higher frequencies from the signal using a band-pass filter $(<5 \mathrm{~Hz},>30 \mathrm{~Hz})$, the foot of the waveform can be identified as the minimum value of the filtered signal. Unlike the derivative method, fluctuations in heart rate do not influence analysis since the frequencies are unaffected (Nichols \& O'Rourke, 2005). When blood velocity signals are collected simultaneously using more than one Doppler probe, time at each site can easily be identified using the maximum or minimum value. When signals are collected sequentially, time at each site is determined using an ECG trace, similar to the online analysis.

\subsubsection{Additional devices for the assessment of regional arterial stiffness}

The assessment of PWV using Doppler ultrasound has been shown to be valid and reliable (Jiang et al., 2008; Sutton-Tyrrell et al., 2001). However, there are several other techniques available for the detection of the pulse wave in the determination of PWV including 
applanation tonometry (as previously described), photoplethysmographic sensors, and magnetic resonance imaging (MRI). Photoplethysmographic sensors contain an infrared emitting diode (peak wavelength $880 \mathrm{~nm}$ ), and a phototransistor detector. The infrared light is either absorbed by the blood and vascular tissue, scattered by other tissues, or reflected back to the detector. The arterial waveform in generated based on how much infrared light is reflected back to the detector (Loukogeorgakis et al., 2002). Flow measurements can also be made using MRI. This technique is capable of providing accurate PWV assessments since distance can be measured along the anatomical segment (Mohiaddin et al., 1993).
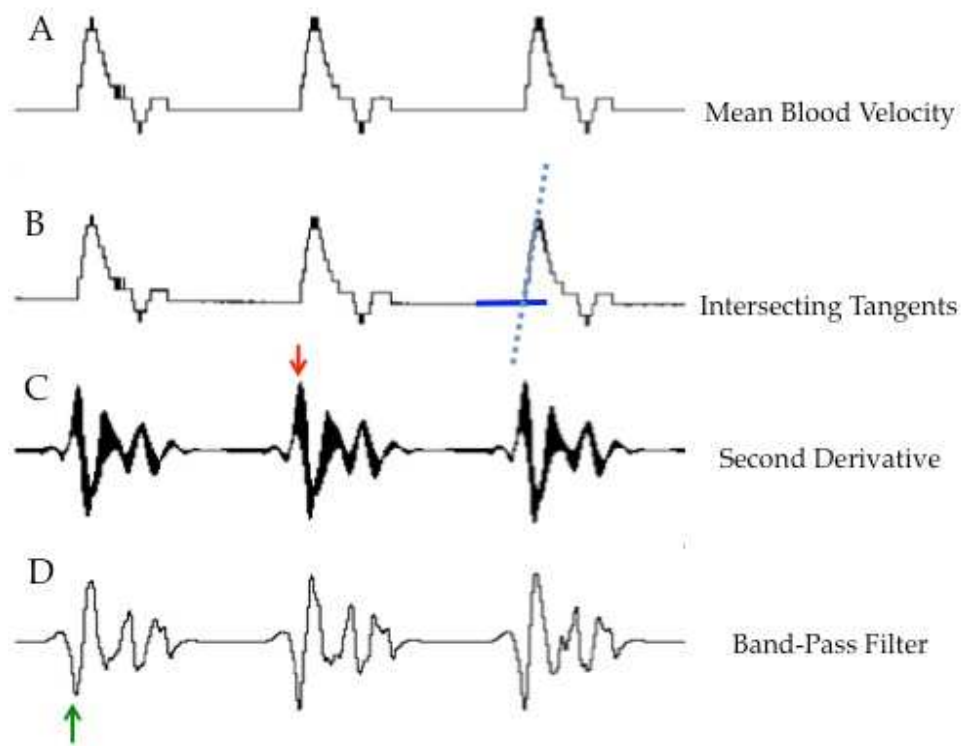

Fig. 8. Various analysis methods for identifying pulse transit time. The arrival of the mean blood velocity waveform (A) is identified with a red arrow. The intersecting tangent (B) analysis locates the point of intersection between the tangent to the initial systolic upstroke of the signal (dotted line), and the horizontal line through the minimum point (closed line). Pulse arrival can also be identified as the maximum value of the second derivative $(\mathrm{C})$, or the minimum value of the band-pass filter (D).

\subsubsection{Limitations of regional arterial stiffness measurements}

PWV does have its limitations. The measurement of distance along the surface of the body is not a true anatomical representative of the arterial segment and therefore can introduce error into the PWV calculation. Pulse wave measurements at the two arterial sites should be collected simultaneously; however, equipment limitations may not permit this. While the collection of sequential measurements is sufficient, caution should be exercised when interpreting results. While MRI assessments of PWV are not subjective to these limitations, the technique is not that widely used given the lack of available equipment and high cost per use. 


\subsubsection{Local versus regional assessment of arterial stiffness}

Aortic stiffness measures (via carotid-femoral PWV) and local carotid measures of distensibility have been compared (Paini et al., 2006). Strong correlations exist between the two measures in healthy subjects, but decrease with an increasing number of comorbidities (hypertension; hypertension and type 2 diabetes), as the aorta stiffens disproportionately to the carotid artery with age and other cardiovascular risk factors (Paini et al., 2006). Stiffness measures at the carotid artery, therefore, seem to provide a strong estimation for aortic stiffness in less diseased individuals, but aortic and carotid stiffness measures should not be used synonymously in higher risk populations.

\section{Arterial stiffness in health and disease}

Indices of arterial stiffness provide a non-invasive assessment of the health of the vasculature, and can provide relevant information about an individual's future risk of morbidity and mortality. While arterial stiffening is primarily attributed to modifications to the intrinsic structure of the vessel, several lifestyle factors can transiently augment or attenuate arterial stiffness. Caffeine consumption (Mahmud \& Feely, 2001), smoking (Mahmud \& Feely, 2003), and resistance exercise (DeVan et al., 2005) have been shown to temporarily increase arterial stiffness, whereas alcohol consumption (Mahmud \& Feely, 2002), food consumption (Ahuja et al., 2009), and aerobic exercise (Kingwell et al., 1997) transiently decrease arterial stiffness. Chronic exposure to these factors, however, can lead to more permanent changes in arterial stiffness. Elevated resting arterial stiffness is observed in habitual smokers and individuals who consume excess caffeine and alcohol. Conversely, individuals who are habitually active, or who undergo an exercise training program are capable of attenuating or reversing age associated increases in arterial stiffness (Tanaka et al., 2000). Resting arterial stiffness is also affected by time of day, with larger arterial diameters and lower blood pressures reported at night (Kool et al., 1992).

Arterial stiffness increases naturally with age (O'Rourke \& Hashimoto, 2007), and the rate of arterial stiffening is often associated with lifestyle factors (discussed above) and disease. Arterial stiffness is present in individuals with congenital diseases such as Marfan syndrome (Hirata et al., 1991), congenital heart diseases including coarctation of the aorta (de Divitiis et al., 2001) and tetralogy of Fallot (Cheung et al., 2006), as well as noncongenital conditions including but not limited to Kawasaki disease (Senzaki et al., 2005) and end-stage renal disease (Blacher et al., 1999). Traditional risk factors for cardiovascular disease are associated with increased arterial stiffening in adults, including obesity (Danias et al., 2003), type 2 diabetes (Henry et al., 2003), hypertension (Ting et al., 1986), and hypercholesterolemia (Wilkinson et al., 2002). Additionally, the presence of atherosclerosis is associated with arterial stiffening at various sites within the vascular tree (van Popele et al., 2001; van Popele et al., 2006). Not surprisingly, elevated arterial stiffness is present in individuals with cardiovascular diseases including coronary artery disease (Weber et al., 2004), heart failure (Kawaguchi et al., 2003), and stroke (Mattace-Raso et al., 2006).

Adolescents and children with cardiovascular disease risk factors including familial hypercholesterolemia (Aggoun et al., 2000), obesity (Tounian et al., 2001), and type 1 diabetes (Heilman et al., 2009) demonstrate greater arterial stiffness than their age and 
gender matched peers. While these studies are cross-sectional in design, and provide no information about their future outcomes, the research suggests children and adolescents with impaired arterial compliance are at a greater risk for disease development in adulthood.

Several investigations have examined the association between indices of arterial stiffness and future risk of cardiovascular morbidity and mortality and all-cause mortality. Aortic (carotid to femoral) PWV is considered the non-invasive gold standard measure of arterial stiffness. In apparently healthy men and women, higher aortic PWV ( $\geq 11.8 \mathrm{~m} / \mathrm{s})$ is associated with a $48 \%$ increased risk of first major cardiovascular disease event including myocardial infarction, unstable angina, heart failure and/or stroke (Mitchell et al., 2010). According to a meta-analysis on aortic PWV, an increase of $1 \mathrm{~m} / \mathrm{s}$ corresponds to an age, gender, and risk factor adjusted risk increase of $15 \%$ for cardiovascular and all-cause mortality (Vlachopoulos et al., 2010). This systematic review included a variety of populations and measurement techniques and therefore provides a comprehensive examination of the risk associated with elevated aortic stiffness. However, there are numerous other studies demonstrating increased risk of mortality in clinical populations with elevated aortic PWV including but not limited to end-stage renal disease (Blacher et al., 1999), hypertension (Laurent et al., 2001), and type 2 diabetes (Cruickshank et al., 2002).

The literature on the relationship between other indices of arterial stiffness and future risk of morbidity and mortality is not as well defined. Some investigations demonstrate no association between decreased carotid artery compliance and distensibility and future risk (Leone et al., 2008; van Dijk et al., 2001), whereas other studies demonstrate elevated risk in individuals with carotid artery stiffness (Barenbrock et al., 2002; Tsivgoulis et al., 2006). Additionally, not all of these investigations used local carotid pulse pressure in the calculation of arterial stiffness; therefore the findings should be interpreted with caution.

\section{Future directions and conclusions}

Efforts have recently been made to establish reference values of arterial stiffness for carotidfemoral PWV (The Reference Values for Arterial Stiffness' Collaboration, 2010). This is an important first step in understanding the baseline changes that occur with arterial stiffness in the healthy person as they age. Furthering these attempts will continue to elucidate the role of stiffness in aging, and will significantly contribute to understanding the role of stiffness in disease. Furthermore, even though stiffness measures have been shown to be strong prognostic indicators for the occurrence of cardiovascular events, work has yet to be done to show if the reduction or attenuation of arterial stiffness is associated with a reduction of cardiovascular events, independent of other risk factors (Laurent \& Boutouyrie, 2007). Indeed, more immediate changes such as reductions in blood pressure, hyperglycemia, and lipids do show reductions in cardiovascular risk scores. However, improvements in the wall of the vessel (stiffness) may in fact suggest more long lasting reductions in cardiovascular risk, but this remains to be seen (Laurent \& Boutouyrie, 2007).

Despite these future considerations, measurement of arterial stiffness is critical in understanding changes in the vascular tree, as its indices can be transiently and chronically altered by aging, disease, and lifestyle factors. Aortic PWV is considered the gold standard for non-invasive assessments of arterial stiffness, and can provide the most relevant 
information about an individual's future risk of cardiovascular morbidity and mortality, and all-cause mortality. Measurement of local arterial stiffness, while requiring more expertise and time, has also emerged as an important tool for the mechanistic study of vascular structure and function, especially in less diseased populations. In combination, these ultrasonic techniques provide a simple, comprehensive, and non-invasive approach to understand arterial structure and function. They should therefore be considered in the study of overall vascular health.

\section{References}

Adji, A., O'Rourke, M. F., \& Namasivayam, M. (2011). Arterial stiffness, its assessment, prognostic value, and implications for treatment. American Journal of Hypertension, Vol. 24, No. 1 (Jan 2011), pp. 5-17. 1941-7225

Aggoun, Y., Bonnet, D., Sidi, D., Girardet, J. P., Brucker, E., Polak, M., Safar, M. E., \& Levy, B. I. (2000). Arterial mechanical changes in children with familial hypercholesterolemia. Arteriosclerosis, Thrombosis, and Vascular Biology, Vol. 20, No. 9 (Sept 2000), pp. 2070-2075. 1524-4636

Ahuja, K. D., Robertson, I. K., \& Ball, M. J. (2009). Acute effects of food on postprandial blood pressure and measures of arterial stiffness in healthy humans. The American Journal of Clinical Nutrition, Vol. 90, No. 2 (Aug 2009), pp. 298-303. 1938-3207

Armentano, R. L., Levenson, J., Barra, J. G., Fischer, E. I., Breitbart, G. J., Pichel, R. H., \& Simon, A. (1991). Assessment of elastin and collagen contribution to aortic elasticity in conscious dogs. American Journal of Physiology, Vol. 260, No. 6 (Jun 1991), pp. H1870-1877. 0002-9513

Atkinson, J. (2008). Age-related medial elastocalcinosis in arteries: mechanisms, animal models, and physiological consequences. Journal of Applied Physiology, Vol. 105, No. 5 (Nov 2008), pp. 1643-1651. 8750-7587

Barenbrock, M., Kosch, M., Joster, E., Kisters, K., Rahn, K. H., \& Hausberg, M. (2002). Reduced arterial distensibility is a predictor of cardiovascular disease in patients after renal transplantation. Journal of Hypertension, Vol. 20, No. 1 (Jan 2002), pp. 7984. 0263-6352

Benetos, A., Laurent, S., Hoeks, A. P., Boutouyrie, P. H., \& Safar, M. E. (1993). Arterial alterations with aging and high blood pressure. A noninvasive study of carotid and femoral arteries. Arteriosclerosis, Thrombosis, and Vascular Biology, Vol. 13, No. 1 (Jan 1993), pp. 90-97. 1049-8834

Blacher, J., Guerin, A. P., Pannier, B., Marchais, S. J., Safar, M. E., \& London, G. M. (1999). Impact of aortic stiffness on survival in end-stage renal disease. Circulation, Vol. 99, No. 18 (May 1999), pp. 2434-2439. 1524-4539

Boutouyrie, P., Bussy, C., Lacolley, P., Girerd, X., Laloux, B., \& Laurent, S. (1999). Association between local pulse pressure, mean blood pressure, and large-artery remodeling. Circulation, Vol. 100, No. 13 (Sept 1999), pp. 1387-1393. 1524-4539

Boutouyrie, P., Laurent, S., Benetos, A., Girerd, X. J., Hoeks, A. P., \& Safar, M. E. (1992). Opposing effects of ageing on distal and proximal large arteries in hypertensives. Journal of Hypertension Supplement, Vol. 10, No. 6 (Aug 1992), pp. S87-91. 0952-1178

Cavalcante, J. L., Lima, J. A., Redheuil, A., \& Al-Mallah, M. H. (2011). Aortic stiffness: current understanding and future directions. Journal of the American College of Cardiology, Vol. 57, No. 14 (Apr 2011), pp. 1511-1522. 1558-3597 
Cheng, K. S., Baker, C. R., Hamilton, G., Hoeks, A. P., \& Seifalian, A. M. (2002). Arterial elastic properties and cardiovascular risk/event. European Journal of Vascular and Endovascular Surgery, Vol. 24, No. 5 (Nov 2002), pp. 383-397. 1078-5884

Cheung, Y. F., Ou, X., \& Wong, S. J. (2006). Central and peripheral arterial stiffness in patients after surgical repair of tetralogy of Fallot: implications for aortic root dilatation. Heart, Vol. 92, No. 12 (Dec 2006), pp. 1827-1830. 1468-201X

Chiu, Y. C., Arand, P. W., Shroff, S. G., Feldman, T., \& Carroll, J. D. (1991). Determination of pulse wave velocities with computerized algorithms. American Heart Journal, Vol. 121, No. 5 (May 1991), pp. 1460-1470. 0002-8703

Cruickshank, K., Riste, L., Anderson, S. G., Wright, J. S., Dunn, G., \& Gosling, R. G. (2002). Aortic pulse-wave velocity and its relationship to mortality in diabetes and glucose intolerance: an integrated index of vascular function? Circulation, Vol. 106, No. 16 (Oct 2002), pp. 2085-2090. 1524-4539

Currie, K. D., Proudfoot, N. A., Timmons, B. W., \& MacDonald, M. J. (2010). Noninvasive measures of vascular health are reliable in preschool-aged children. Applied Physiology, Nutrition, and Metabolism, Vol. 35, No. 4 (Aug 2010), pp. 512-517. 17155312

Danias, P. G., Tritos, N. A., Stuber, M., Botnar, R. M., Kissinger, K. V., \& Manning, W. J. (2003). Comparison of aortic elasticity determined by cardiovascular magnetic resonance imaging in obese versus lean adults. American Journal of Cardiology, Vol. 91, No. 2 (Jan 2003), pp. 195-199. 0002-9149

Davies, J. I., \& Struthers, A. D. (2003). Pulse wave analysis and pulse wave velocity: a critical review of their strengths and weaknesses. Journal of Hypertension, Vol. 21, No. 3 (Mar 2003), pp. 463-472. 0263-6352

de Divitiis, M., Pilla, C., Kattenhorn, M., Zadinello, M., Donald, A., Leeson, P., Wallace, S., Redington, A., \& Deanfield, J. E. (2001). Vascular dysfunction after repair of coarctation of the aorta: impact of early surgery. Circulation, Vol. 104, No. 12 (Sep 2001), pp. I165-170. 1524-4539

Dernellis, J., \& Panaretou, M. (2005). Aortic stiffness is an independent predictor of progression to hypertension in nonhypertensive subjects. Hypertension, Vol. 45, No. 3 (Mar 2005), pp. 426-431. 1524-4563

DeVan, A. E., Anton, M. M., Cook, J. N., Neidre, D. B., Cortez-Cooper, M. Y., \& Tanaka, H. (2005). Acute effects of resistance exercise on arterial compliance. Journal of Applied Physiology, Vol. 98, No. 6 (Jun 2005), pp. 2287-2291. 8750-7587

Dijk, J. M., Algra, A., van der Graaf, Y., Grobbee, D. E., \& Bots, M. L. (2005). Carotid stiffness and the risk of new vascular events in patients with manifest cardiovascular disease. The SMART study. European Heart Journal, Vol. 26, No. 12 (Jun 2005), pp. 1213-1220. 0195-668X

Dobrin, P. B. (1999). Distribution of lamellar deformations: implications for properties of the arterial media. Hypertension, Vol. 33, No. 3 (Mar 1999), pp. 806-810. 0194-911X

Folkow, B. (1995). Hypertensive structural changes in systemic precapillary resistance vessels: how important are they for in vivo haemodynamics? Journal of Hypertension, Vol. 13, No. 12 (Dec 1995), pp. 1546-1559. 0263-6352

Gamble, G., Zorn, J., Sanders, G., MacMahon, S., \& Sharpe, N. (1994). Estimation of arterial stiffness, compliance, and distensibility from M-mode ultrasound measurements of the common carotid artery. Stroke, Vol. 25, No. 1 (Jan 1994), pp. 11-16. 0039-2499 
Harkness, M. L., Harkness, R. D., \& McDonald, D. A. (1957). The collagen and elastin content of the arterial wall in the dog. Proceedings of the Royal Society of London, Series B. Containing papers of a Biological character, Vol. 146, No. 925 (Jun 1957), pp. 541-551. 0080-4649

Hayoz, D., Tardy, Y., Rutschmann, B., Mignot, J. P., Achakri, H., Feihl, F., Meister, J. J., Waeber, B., \& Brunner, H. R. (1993). Spontaneous diameter oscillations of the radial artery in humans. American Journal of Physiology, Vol. 264, No. 6 (Jun 1993), pp. H2080-2084. 0002-9513

Heilman, K., Zilmer, M., Zilmer, K., Lintrop, M., Kampus, P., Kals, J., \& Tillmann, V. (2009). Arterial stiffness, carotid artery intima-media thickness and plasma myeloperoxidase level in children with type 1 diabetes. Diabetes Research and Clinical Practice, Vol. 84, No. 2 (May 2009), pp. 168-173. 1872-8227

Henry, R. M., Kostense, P. J., Spijkerman, A. M., Dekker, J. M., Nijpels, G., Heine, R. J., Kamp, O., Westerhof, N., Bouter, L. M., \& Stehouwer, C. D. (2003). Arterial stiffness increases with deteriorating glucose tolerance status: the Hoorn Study. Circulation, Vol. 107, No. 16 (Apr 2003), pp. 2089-2095. 1524-4539

Hirai, T., Sasayama, S., Kawasaki, T., \& Yagi, S. (1989). Stiffness of systemic arteries in patients with myocardial infarction. A noninvasive method to predict severity of coronary atherosclerosis. Circulation, Vol. 80, No. 1 (Jul 1989), pp. 78-86. 0009-7322

Hirata, K., Triposkiadis, F., Sparks, E., Bowen, J., Wooley, C. F., \& Boudoulas, H. (1991). The Marfan syndrome: abnormal aortic elastic properties. Journal of the American College of Cardiology, Vol. 18, No. 1 (Jul 1991), pp. 57-63. 0735-1097

Hoeks, A. P., Brands, P. J., Smeets, F. A., \& Reneman, R. S. (1990). Assessment of the distensibility of superficial arteries. Ultrasound in Medicine $\mathcal{E}$ Biology, Vol. 16, No. 2 1990), pp. 121-128. 0301-5629

Hoeks, A. P., Willekes, C., Boutouyrie, P., Brands, P. J., Willigers, J. M., \& Reneman, R. S. (1997). Automated detection of local artery wall thickness based on M-line signal processing. Ultrasound in Medicine \& Biology, Vol. 23, No. 7 (1997), pp. 1017-1023. 0301-5629

Jiang, B., Liu, B., McNeill, K. L., \& Chowienczyk, P. J. (2008). Measurement of pulse wave velocity using pulse wave Doppler ultrasound: comparison with arterial tonometry. Ultrasound in Medicine \& Biology, Vol. 34, No. 3 (Mar 2008), pp. 509-512. 0301-5629

Kanters, S. D., Elgersma, O. E., Banga, J. D., van Leeuwen, M. S., \& Algra, A. (1998). Reproducibility of measurements of intima-media thickness and distensibility in the common carotid artery. European Journal of Vascular E Endovascular Surgery, Vol. 16, No. 1 (Jul 1998), pp. 28-35. 1078-5884

Kawaguchi, M., Hay, I., Fetics, B., \& Kass, D. A. (2003). Combined ventricular systolic and arterial stiffening in patients with heart failure and preserved ejection fraction: implications for systolic and diastolic reserve limitations. Circulation, Vol. 107, No. 5 (Feb 2003), pp. 714-720. 1524-4539

Kelly, A. S., Kaiser, D. R., Dengel, D. R., \& Bank, A. J. (2004). Comparison of B-mode and echo tracking methods of assessing flow-mediated dilation. Ultrasound in Medicine E Biology, Vol. 30, No. 11 (Nov 2004), pp. 1447-1449. 0301-5629

Kelly, R., \& Fitchett, D. (1992). Noninvasive determination of aortic input impedance and external left ventricular power output: a validation and repeatability study of a 
new technique. Journal of the American College of Cardiology, Vol. 20, No. 4 (Oct 1992), pp. 952-963. 0735-1097

Kelly, R., Hayward, C., Avolio, A., \& O'Rourke, M. (1989). Noninvasive determination of age-related changes in the human arterial pulse. Circulation, Vol. 80, No. 6 (Dec 1989), pp. 1652-1659. 0009-7322

Kingwell, B. A., Berry, K. L., Cameron, J. D., Jennings, G. L., \& Dart, A. M. (1997). Arterial compliance increases after moderate-intensity cycling. Am J Physiol, Vol. 273, No. 5 (Nov 1997), pp. H2186-2191. 0002-9513

Kool, M. J., Struijker-Boudier, H. A., Wijnen, J. A., Hoeks, A. P., \& van Bortel, L. M. (1992). Effects of diurnal variability and exercise training on properties of large arteries. Journal of Hypertension Supplement, Vol. 10, No. 6 (Aug 1992), pp. S49-52. 0952-1178

Lanne, T., Sonesson, B., Bergqvist, D., Bengtsson, H., \& Gustafsson, D. (1992). Diameter and compliance in the male human abdominal aorta: influence of age and aortic aneurysm. European Journal of Vascular Surgery, Vol. 6, No. 2 (Mar 1992), pp. 178184. 0950-821X

Laurent, S., \& Boutouyrie, P. (2007). Recent advances in arterial stiffness and wave reflection in human hypertension. Hypertension, Vol. 49, No. 6 (Jun 2007), pp. 1202-1206. 15244563

Laurent, S., Boutouyrie, P., Asmar, R., Gautier, I., Laloux, B., Guize, L., Ducimetiere, P., \& Benetos, A. (2001). Aortic stiffness is an independent predictor of all-cause and cardiovascular mortality in hypertensive patients. Hypertension, Vol. 37, No. 5 (May 2001), pp. 1236-1241. 1524-4563

Laurent, S., Boutouyrie, P., \& Lacolley, P. (2005). Structural and genetic bases of arterial stiffness. Hypertension, Vol. 45, No. 6 (Jun 2005), pp. 1050-1055. 1524-4563

Laurent, S., Cockcroft, J., Van Bortel, L., Boutouyrie, P., Giannattasio, C., Hayoz, D., Pannier, B., Vlachopoulos, C., Wilkinson, I., \& Struijker-Boudier, H. (2006). Expert consensus document on arterial stiffness: methodological issues and clinical applications. European Heart Journal, Vol. 27, No. 21 (Nov 2006), pp. 2588-2605. 0195-668X

Learoyd, B. M., \& Taylor, M. G. (1966). Alterations with age in the viscoelastic properties of human arterial walls. Circulation Research, Vol. 18, No. 3 (Mar 1966), pp. 278-292. 0009-7330

Lee, H. Y., \& Oh, B. H. (2010). Aging and arterial stiffness. Circulation Journal, Vol. 74, No. 11 (Nov 2010), pp. 2257-2262. 1347-4820

Lehmann, E. D., Hopkins, K. D., Rawesh, A., Joseph, R. C., Kongola, K., Coppack, S. W., \& Gosling, R. G. (1998). Relation between number of cardiovascular risk factors/events and noninvasive Doppler ultrasound assessments of aortic compliance. Hypertension, Vol. 32, No. 3 (Sept 1998), pp. 565-569. 0194-911X

Leone, N., Ducimetiere, P., Gariepy, J., Courbon, D., Tzourio, C., Dartigues, J. F., Ritchie, K., Alperovitch, A., Amouyel, P., Safar, M. E., \& Zureik, M. (2008). Distension of the carotid artery and risk of coronary events: the three-city study. Arteriosclerosis, Thrombosis, and Vascular Biology, Vol. 28, No. 7 (Jul 2008), pp. 1392-1397. 1524-4636

Levy, D., \& Brink, S. (2005). A Change of Heart: How the People of Framingham, Massachusetts, Helped Unravel the Mysteries of Cardiovascular Disease (1st edition), Knopf, 0375412751, New York

Liang, Y. L., Teede, H., Kotsopoulos, D., Shiel, L., Cameron, J. D., Dart, A. M., \& McGrath, B. P. (1998). Non-invasive measurements of arterial structure and function: 
repeatability, interrelationships and trial sample size. Clinical Science (London), Vol. 95, No. 6 (Dec 1998), pp. 669-679. 0143-5221

London, G. M., \& Pannier, B. (2010). Arterial functions: how to interpret the complex physiology. Nephrology, Dialysis, Transplantation, Vol. 25, No. 12 (Dec 2010), pp. 3815-3823. 1460-2385

Loukogeorgakis, S., Dawson, R., Phillips, N., Martyn, C. N., \& Greenwald, S. E. (2002). Validation of a device to measure arterial pulse wave velocity by a photoplethysmographic method. Physiological Measurements, Vol. 23, No. 3 (Aug 2002), pp. 581-596. 0967-3334

Mahmud, A., \& Feely, J. (2001). Acute effect of caffeine on arterial stiffness and aortic pressure waveform. Hypertension, Vol. 38, No. 2 (Aug 2001), pp. 227-231. 1524-4563

Mahmud, A., \& Feely, J. (2002). Divergent effect of acute and chronic alcohol on arterial stiffness. American Journal of Hypertension, Vol. 15, No. 3 (Mar 2002), pp. 240-243. 0895-7061

Mahmud, A., \& Feely, J. (2003). Effect of smoking on arterial stiffness and pulse pressure amplification. Hypertension, Vol. 41, No. 1 (Jan 2003), pp. 183-187. 1524-4563

Mattace-Raso, F. U., van der Cammen, T. J., Hofman, A., van Popele, N. M., Bos, M. L., Schalekamp, M. A., Asmar, R., Reneman, R. S., Hoeks, A. P., Breteler, M. M., \& Witteman, J. C. (2006). Arterial stiffness and risk of coronary heart disease and stroke: the Rotterdam Study. Circulation, Vol. 113, No. 5 (Feb 2006), pp. 657-663. 1524-4539

McDonald, D. A. (1968). Regional pulse-wave velocity in the arterial tree. Journal of Applied Physiology, Vol. 24, No. 1 (Jan 1968), pp. 73-78. 0021-8987

McEniery, C. M., Spratt, M., Munnery, M., Yarnell, J., Lowe, G. D., Rumley, A., Gallacher, J., Ben-Shlomo, Y., Cockcroft, J. R., \& Wilkinson, I. B. (2010). An analysis of prospective risk factors for aortic stiffness in men: 20-year follow-up from the Caerphilly prospective study. Hypertension, Vol. 56, No. 1 (Jul 2010), pp. 36-43. 1524-4563

Meinders, J. M., \& Hoeks, A. P. (2004). Simultaneous assessment of diameter and pressure waveforms in the carotid artery. Ultrasound in Medicine $\mathcal{E}$ Biology, Vol. 30, No. 2 (Feb 2004), pp. 147-154. 0301-5629

Mitchell, G. F., Hwang, S. J., Vasan, R. S., Larson, M. G., Pencina, M. J., Hamburg, N. M., Vita, J. A., Levy, D., \& Benjamin, E. J. (2010). Arterial stiffness and cardiovascular events: the Framingham Heart Study. Circulation, Vol. 121, No. 4 (Feb 2010), pp. 505-511. 1524-4539

Mohiaddin, R. H., Firmin, D. N., \& Longmore, D. B. (1993). Age-related changes of human aortic flow wave velocity measured noninvasively by magnetic resonance imaging. Journal of Applied Physiology, Vol. 74, No. 1 (Jan 1993), pp. 492-497. 8750-7587

Molinari, F., Zeng, G., \& Suri, J. S. (2010). A state of the art review on intima-media thickness (IMT) measurement and wall segmentation techniques for carotid ultrasound. Computer Methods and Programs in Biomedicine, Vol. 100, No. 3 (Dec 2010), pp. 201221. 1872-7565

Munakata, M., Ito, N., Nunokawa, T., \& Yoshinaga, K. (2003). Utility of automated brachial ankle pulse wave velocity measurements in hypertensive patients. American Journal of Hypertension, Vol. 16, No. 8 (Aug 2003), pp. 653-657. 0895-7061 
Naghavi, M. (2009). Asymptomatic Atherosclerosis (1st edition), Humana Press, 9781603271783, New York

Naidu, M. U., Reddy, B. M., Yashmaina, S., Patnaik, A. N., \& Rani, P. U. (2005). Validity and reproducibility of arterial pulse wave velocity measurement using new device with oscillometric technique: a pilot study. Biomedical Engineering Online, Vol. 4, No. (2005), pp. 49. 1475-925X

Najjar, S. S., Scuteri, A., \& Lakatta, E. G. (2005). Arterial aging: is it an immutable cardiovascular risk factor? Hypertension, Vol. 46, No. 3 (Sept 2005), pp. 454-462. 1524-4563

Nichols, W. W., \& O'Rourke, M. F. (2005). McDonald's Blood Flow in Arteries: Theoretical, Experimental and Clinical Principles (5th edition), Hodder Arnold, 0340809418, London

Nualnim, N., Barnes, J. N., Tarumi, T., Renzi, C. P., \& Tanaka, H. (2011). Comparison of central artery elasticity in swimmers, runners, and the sedentary. American Journal of Cardiology, Vol. 107, No. 5 (Mar 2011), pp. 783-787. 1879-1913

O'Leary, D. H., Polak, J. F., Kronmal, R. A., Manolio, T. A., Burke, G. L., \& Wolfson, S. K., Jr. (1999). Carotid-artery intima and media thickness as a risk factor for myocardial infarction and stroke in older adults. Cardiovascular Health Study Collaborative Research Group. New England Journal of Medicine, Vol. 340, No. 1 (Jan 1999), pp. 1422. 0028-4793

O'Rourke, M. F. (2006). Principles and definitions of arterial stiffness, wave reflections and pulse pressure amplification, In: Arterial Stiffness in Hypertension, Safar, M. E. \& O'Rourke, M. F., pp. 3-20, Elsevier, Amsterdam

O'Rourke, M. F., \& Hashimoto, J. (2007). Mechanical factors in arterial aging: a clinical perspective. Journal of the American College of Cardiology, Vol. 50, No. 1 (Jul 2007), pp. 1-13. 1558-3597

O'Rourke, M. F., \& Safar, M. E. (2005). Relationship between aortic stiffening and microvascular disease in brain and kidney: cause and logic of therapy. Hypertension, Vol. 46, No. 1 (Jul 2005), pp. 200-204. 1524-4563

O'Rourke, M. F., Staessen, J. A., Vlachopoulos, C., Duprez, D., \& Plante, G. E. (2002). Clinical applications of arterial stiffness; definitions and reference values. American Journal of Hypertension, Vol. 15, No. 5 (May 2002), pp. 426-444. 0895-7061

Paini, A., Boutouyrie, P., Calvet, D., Tropeano, A. I., Laloux, B., \& Laurent, S. (2006). Carotid and aortic stiffness: determinants of discrepancies. Hypertension, Vol. 47, No. 3 (Mar 2006), pp. 371-376. 1524-4563

Pannier, B. M., Avolio, A. P., Hoeks, A., Mancia, G., \& Takazawa, K. (2002). Methods and devices for measuring arterial compliance in humans. American Journal of Hypertension, Vol. 15, No. 8 (Aug 2002), pp. 743-753. 0895-7061

Papaioannou, T. G., Stamatelopoulos, K. S., Gialafos, E., Vlachopoulos, C., Karatzis, E., Nanas, J., \& Lekakis, J. (2004). Monitoring of arterial stiffness indices by applanation tonometry and pulse wave analysis: reproducibility at low blood pressures. Journal of Clinical Monitoring and Computing, Vol. 18, No. 2 (Apr 2004), pp. 137-144. 1387-1307

Peters, S. A., den Ruijter, H. M., Palmer, M. K., Grobbee, D. E., Crouse, J. R., 3rd, O'Leary, D. H., Evans, G. W., Raichlen, J. S., Lind, L., \& Bots, M. L. (2011). Manual or semiautomated edge detection of the maximal far wall common carotid intima-media 
thickness: a direct comparison. Journal of Internal Medicine, Vol. No. (Jul 2011), pp. 1365-2796

Peterson, L. H., Jensen, R. E., \& Parnell, J. (1960). Mechanical Properties of Arteries in Vivo. Circulation Research, Vol. 8, No. 3 (May 1960), pp. 622-639.

Redheuil, A., Yu, W. C., Wu, C. O., Mousseaux, E., de Cesare, A., Yan, R., Kachenoura, N., Bluemke, D., \& Lima, J. A. (2010). Reduced ascending aortic strain and distensibility: earliest manifestations of vascular aging in humans. Hypertension, Vol. 55, No. 2 (Feb 2010), pp. 319-326. 1524-4563

Reneman, R. S., Meinders, J. M., \& Hoeks, A. P. (2005). Non-invasive ultrasound in arterial wall dynamics in humans: what have we learned and what remains to be solved. European Heart Journal, Vol. 26, No. 10 (May 2005), pp. 960-966. 0195-668X

Roman, M. J., Devereux, R. B., Schwartz, J. E., Lockshin, M. D., Paget, S. A., Davis, A., Crow, M. K., Sammaritano, L., Levine, D. M., Shankar, B. A., Moeller, E., \& Salmon, J. E. (2005). Arterial stiffness in chronic inflammatory diseases. Hypertension, Vol. 46, No. 1 (Jul 2005), pp. 194-199. 1524-4563

Saito, M., Okayama, H., Nishimura, K., Ogimoto, A., Ohtsuka, T., Inoue, K., Hiasa, G., Sumimoto, T., \& Higaki, J. (2008). Possible link between large artery stiffness and coronary flow velocity reserve. Heart, Vol. 94, No. 6 (Jun 2008), pp. e20. 1468-201X

Senzaki, H., Chen, C. H., Ishido, H., Masutani, S., Matsunaga, T., Taketazu, M., Kobayashi, T., Sasaki, N., Kyo, S., \& Yokote, Y. (2005). Arterial hemodynamics in patients after Kawasaki disease. Circulation, Vol. 111, No. 16 (Apr 2005), pp. 2119-2125. 1524-4539

Simon, A., Gariepy, J., Chironi, G., Megnien, J. L., \& Levenson, J. (2002). Intima-media thickness: a new tool for diagnosis and treatment of cardiovascular risk. Journal of Hypertension, Vol. 20, No. 2 (Feb 2002), pp. 159-169. 0263-6352

Sutton-Tyrrell, K., Mackey, R. H., Holubkov, R., Vaitkevicius, P. V., Spurgeon, H. A., \& Lakatta, E. G. (2001). Measurement variation of aortic pulse wave velocity in the elderly. American Journal of Hypertension, Vol. 14, No. 5 (May 2001), pp. 463-468. 0895-7061

Taddei, S., Virdis, A., Ghiadoni, L., Salvetti, G., Bernini, G., Magagna, A., \& Salvetti, A. (2001). Age-related reduction of NO availability and oxidative stress in humans. Hypertension, Vol. 38, No. 2 (Aug 2001), pp. 274-279. 1524-4563

Tanaka, H., Dinenno, F. A., Monahan, K. D., Clevenger, C. M., DeSouza, C. A., \& Seals, D. R. (2000). Aging, habitual exercise, and dynamic arterial compliance. Circulation, Vol. 102, No. 11 (Sept 2000), pp. 1270-1275. 1524-4539

Tardy, Y., Meister, J. J., Perret, F., Brunner, H. R., \& Arditi, M. (1991). Non-invasive estimate of the mechanical properties of peripheral arteries from ultrasonic and photoplethysmographic measurements. Clinical Physics and Physiological Measurement, Vol. 12, No. 1 (Feb 1991), pp. 39-54. 0143-0815

The Reference Values for Arterial Stiffness' Collaboration. (2010). Determinants of pulse wave velocity in healthy people and in the presence of cardiovascular risk factors: 'establishing normal and reference values'. European Heart Journal, Vol. 31, No. 19 (Oct 2010), pp. 2338-2350. 1522-9645

Ting, C. T., Brin, K. P., Lin, S. J., Wang, S. P., Chang, M. S., Chiang, B. N., \& Yin, F. C. (1986). Arterial hemodynamics in human hypertension. The Journal of Clinical Investigations, Vol. 78, No. 6 (Dec 1986), pp. 1462-1471. 0021-9738 
Tounian, P., Aggoun, Y., Dubern, B., Varille, V., Guy-Grand, B., Sidi, D., Girardet, J. P., \& Bonnet, D. (2001). Presence of increased stiffness of the common carotid artery and endothelial dysfunction in severely obese children: a prospective study. Lancet, Vol. 358, No. 9291 (Oct 2001), pp. 1400-1404. 0140-6736

Tsivgoulis, G., Vemmos, K., Papamichael, C., Spengos, K., Daffertshofer, M., Cimboneriu, A., Zis, V., Lekakis, J., Zakopoulos, N., \& Mavrikakis, M. (2006). Common carotid arterial stiffness and the risk of ischaemic stroke. European Journal of Neurology, Vol. 13, No. 5 (May 2006), pp. 475-481. 1351-5101

Van Bortel, L. M., Balkestein, E. J., van der Heijden-Spek, J. J., Vanmolkot, F. H., Staessen, J. A., Kragten, J. A., Vredeveld, J. W., Safar, M. E., Struijker Boudier, H. A., \& Hoeks, A. P. (2001). Non-invasive assessment of local arterial pulse pressure: comparison of applanation tonometry and echo-tracking. Journal of Hypertension, Vol. 19, No. 6 (Jun 2001), pp. 1037-1044. 0263-6352

Van Bortel, L. M., Duprez, D., Starmans-Kool, M. J., Safar, M. E., Giannattasio, C., Cockcroft, J., Kaiser, D. R., \& Thuillez, C. (2002). Clinical applications of arterial stiffness, Task Force III: recommendations for user procedures. American Journal of Hypertension, Vol. 15, No. 5 (May 2002), pp. 445-452. 0895-7061

van Dijk, R. A., Dekker, J. M., Nijpels, G., Heine, R. J., Bouter, L. M., \& Stehouwer, C. D. (2001). Brachial artery pulse pressure and common carotid artery diameter: mutually independent associations with mortality in subjects with a recent history of impaired glucose tolerance. European Journal of Clinical Investigations, Vol. 31, No. 9 (Sept 2001), pp. 756-763. 0014-2972

van Popele, N. M., Grobbee, D. E., Bots, M. L., Asmar, R., Topouchian, J., Reneman, R. S., Hoeks, A. P., van der Kuip, D. A., Hofman, A., \& Witteman, J. C. (2001). Association Between Arterial Stiffness and Atherosclerosis: The Rotterdam Study. Stroke, Vol. 32, No. 2 (2001), pp. 454-460.

van Popele, N. M., Mattace-Raso, F. U., Vliegenthart, R., Grobbee, D. E., Asmar, R., van der Kuip, D. A., Hofman, A., de Feijter, P. J., Oudkerk, M., \& Witteman, J. C. (2006). Aortic stiffness is associated with atherosclerosis of the coronary arteries in older adults: the Rotterdam Study. Journal of Hypertension, Vol. 24, No. 12 (2006), pp. 2371-2376.

Vlachopoulos, C., Aznaouridis, K., \& Stefanadis, C. (2010). Prediction of cardiovascular events and all-cause mortality with arterial stiffness: a systematic review and metaanalysis. Journal of the American College of Cardiology, Vol. 55, No. 13 (Mar 2010), pp. 1318-1327. 1558-3597

Vlachopoulos, C., Dima, I., Aznaouridis, K., Vasiliadou, C., Ioakeimidis, N., Aggeli, C., Toutouza, M., \& Stefanadis, C. (2005). Acute systemic inflammation increases arterial stiffness and decreases wave reflections in healthy individuals. Circulation, Vol. 112, No. 14 (Oct 2005), pp. 2193-2200. 1524-4539

Weber, T., Ammer, M., Rammer, M., Adji, A., O'Rourke, M. F., Wassertheurer, S., Rosenkranz, S., \& Eber, B. (2009). Noninvasive determination of carotid-femoral pulse wave velocity depends critically on assessment of travel distance: a comparison with invasive measurement. Journal of Hypertension, Vol. 27, No. 8 (Aug 2009), pp. 1624-1630. 1473-5598 
Weber, T., Auer, J., O'Rourke, M. F., Kvas, E., Lassnig, E., Berent, R., \& Eber, B. (2004). Arterial stiffness, wave reflections, and the risk of coronary artery disease. Circulation, Vol. 109, No. 2 (Jan 2004), pp. 184-189. 1524-4539

Widlansky, M. E., Gokce, N., Keaney, J. F., Jr., \& Vita, J. A. (2003). The clinical implications of endothelial dysfunction. Journal of the American College of Cardiology, Vol. 42, No. 7 (Oct 2003), pp. 1149-1160. 0735-1097

Wilkinson, I. B., Mohammad, N. H., Tyrrell, S., Hall, I. R., Webb, D. J., Paul, V. E., Levy, T., \& Cockcroft, J. R. (2002). Heart rate dependency of pulse pressure amplification and arterial stiffness. American Journal of Hypertension, Vol. 15, No. 1 (Jan 2002), pp. 24-30. 0895-7061

Wilkinson, I. B., Prasad, K., Hall, I. R., Thomas, A., MacCallum, H., Webb, D. J., Frenneaux, M. P., \& Cockcroft, J. R. (2002). Increased central pulse pressure and augmentation index in subjects with hypercholesterolemia. Journal of the American College of Cardiology, Vol. 39, No. 6 (Mar 2002), pp. 1005-1011. 0735-1097

Woodman, R. J., Playford, D. A., Watts, G. F., Cheetham, C., Reed, C., Taylor, R. R., Puddey, I. B., Beilin, L. J., Burke, V., Mori, T. A., \& Green, D. (2001). Improved analysis of brachial artery ultrasound using a novel edge-detection software system. Journal of Applied Physiology, Vol. 91, No. 2 (Aug 2001), pp. 929-937. 8750-7587

Zieman, S. J., Melenovsky, V., \& Kass, D. A. (2005). Mechanisms, pathophysiology, and therapy of arterial stiffness. Arteriosclerosis, Thrombosis, and Vascular Biology, Vol. 25, No. 5 (May 2005), pp. 932-943. 1524-4636 


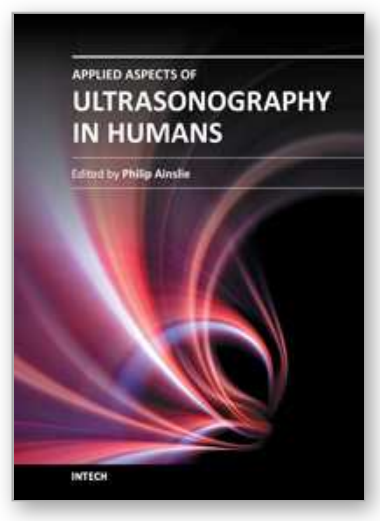

\section{Applied Aspects of Ultrasonography in Humans \\ Edited by Prof. Philip Ainslie}

ISBN 978-953-51-0522-0

Hard cover, 190 pages

Publisher InTech

Published online 25, April, 2012

Published in print edition April, 2012

Written by international experts, this publication provides the reader with the present knowledge and future research directions of diagnostic and therapeutic ultrasound and spectroscopy. Focused topics include Duplex ultrasound, transcranial color Duplex, MRA guided Doppler ultrasonography and near-infrared spectroscopy. New directions in the use and application of transcranial and color Duplex ultrasound are provided, as well as the use of ultrasound and arterial stiffness for measuring human vascular health and circulatory control. Novel use of ultrasound for the detection of intra-cardiac and intra-pulmonary shunts is also described along with its utility for the assessment of gastric regulation and emptying.

\section{How to reference}

In order to correctly reference this scholarly work, feel free to copy and paste the following:

Graeme J. Koelwyn, Katharine D. Currie, Maureen J. MacDonald and Neil D. Eves (2012). Ultrasonography and Tonometry for the Assessment of Human Arterial Stiffness, Applied Aspects of Ultrasonography in Humans, Prof. Philip Ainslie (Ed.), ISBN: 978-953-51-0522-0, InTech, Available from:

http://www.intechopen.com/books/applied-aspects-of-ultrasonography-in-humans/ultrasonography-andtonometry-for-the-assessment-of-human-arterial-stiffness

\section{INTECH}

open science | open minds

\author{
InTech Europe \\ University Campus STeP Ri \\ Slavka Krautzeka 83/A \\ 51000 Rijeka, Croatia \\ Phone: +385 (51) 770447 \\ Fax: +385 (51) 686166 \\ www.intechopen.com
}

\author{
InTech China \\ Unit 405, Office Block, Hotel Equatorial Shanghai \\ No.65, Yan An Road (West), Shanghai, 200040, China \\ 中国上海市延安西路65号上海国际贵都大饭店办公楼 405 单元 \\ Phone: +86-21-62489820 \\ Fax: +86-21-62489821
}


(C) 2012 The Author(s). Licensee IntechOpen. This is an open access article distributed under the terms of the Creative Commons Attribution 3.0 License, which permits unrestricted use, distribution, and reproduction in any medium, provided the original work is properly cited. 